\title{
Multinomial Logistic Regression Model for Assessing Factors Associated with Junk Food Consumption of Secondary Level Students
}

\author{
Srijana Subedi ${ }^{*}$ and Madhav Kumar Bhusal2
}

Submitted: 6 August 202I; Accepted: 4 October 2021

Published online: 5 December 2021

DOI: https://doi.org//0.3126/njs.v5il.4I227

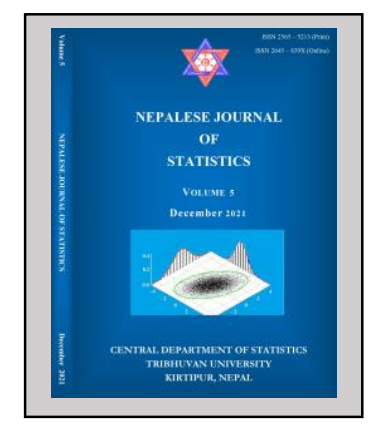

\begin{abstract}
Background: Globalization, economic progress, urbanization, and industrialization have ushered in considerable changes in lifestyles and diet regimes. Consumption of junk food has surged at a rapid pace nowadays. In Nepal, there is a lack of sufficient research regarding junk food practices and persuading factors for its consumption, among teenage students. It is a global concern and has threatened the health of many people.

Objective: This research aims to explore the factors associated with junk food consumption among students of secondary level in Ratnanagar Municipality of Chitwan.

Materials and Methods: A cross-sectional research design consisting of $37 \mathrm{I}$ secondary level students, and selection based on primary data collection method by the researchers was used in this study. The data was analyzed using descriptive as well as an inferential statistical method. To find the association of different factors with junk food consumption levels (Low, Moderate, and High) multinomial logistic regression model (MLRM) was used, and the goodness of fit of the model was assessed.
\end{abstract}

Results: The fitted MLRM satisfied the criteria of the diagnostic test including a test of goodness of fit, multi-collinearity test, and minimum criteria of the model utilization with the classification accuracy of $55 \%$. The variables like family monthly income $(O R=1.0000 \mathrm{I}, \mathrm{C} . \mathrm{I}=\mathrm{I} .00000 \mathrm{I}$ $\mathrm{I} .000020)$, students' daily pocket money $(\mathrm{OR}=\mathrm{I} .02$, $C . \mathrm{I}=\mathrm{I} .007-\mathrm{I} .033)$, gender $(\mathrm{OR}=0.354$, C.I= 0.179 - 0.7), knowledge regarding junk food consumption ( $O R=2.744, C . I=I .366-5.5 \mathrm{I} I)$, attitude towards food choice ( $O R=2.487, C . I=I .288$ - 4.803), friend's encouragement for junk food consumption $(\mathrm{OR}=0.178, \mathrm{C} . \mathrm{I}=0.045-0.70 \mathrm{I})$, and occupation of father (business) $(\mathrm{OR}=2.867$, $C . I=I .084-7.58 I)$ are seen to be significant to the model High versus Low consumption. Students' daily pocket money $(\mathrm{OR}=\mathrm{I} .0 \mathrm{I} 2, \mathrm{C} . \mathrm{I}=\mathrm{I} .002-\mathrm{I} .023)$, knowledge regarding junk food consumption $(O R=2.427, C . I=I .293-4.553)$, restrictive food parenting practice $(O R=2.228, C . I=0.945-5.253)$, friend's encouragement for junk food consumption $(O R=0.252, C . I=0.067-0.944)$, recognition of marketing promotion strategy $(O R=0.523, C . I=0.295-0.928)$, educational level of mother (lower secondary level) $(O R=5.465, C . I=I .069-27.952)$, occupation of father (business) ( $O R=2.47$, $C . I=I .056-5.777)$ are seen to be significant to the model Moderate versus Low consumption.

Conclusion: Study revealed that more than one-fourth of the sampled students were high consumers of junk foods. Many factors are associated with the consumption of junk foods. Thus, 
addressing the issue of increasing consumption, developing strategies \& conducting different research in this field is the must. Concerned authorities should also pay special attention to this subject matter.

Keywords: Chi-square test, goodness of fit test, junk food consumption level, multinomial logistic regression, odds ratio, secondary level students.

Address correspondence to the author: Central Department of Statistics, Tribhuvan University, Kirtipur, Nepal', . Email: srijanasubedi854@gmail.com ${ }^{\prime *}$ (Corresponding author email); madhav.bhusal@cds.tu.edu.np ${ }^{2}$

\section{INTRODUCTION}

The junk food industry is a rapidly growing industry, and it has replaced nutritious foods in our diets. Since health is wealth, eating healthy \& living healthy should be the main motto of our life. Unfortunately, the world has adapted to unhealthy eating habits nowadays. Accelerating globalization, economic progress, urbanization, and industrialization have all influenced the dietary lifestyle of people. These changes, in particular, have impacted people's health in developing and transitioning nations (FAO/WHO, 2003, p. 140). The term junk food is inherently colloquial (Hadjikakou and Baker, 2019). Palatable but unwholesome foods rife in fat, salt, and sugar (HFSS) and scarce in nutrients like proteins, vitamins, minerals, and fibers are junk foods (Stedman, 20I2). Junk food has been interpreted and defined from a different perspective depending on its incidence in the literature. From a nutrition-related perspective, junk foods are non-core/nutrient-poor foods that imply non-advantageous foods for health (Bell, Kremer, Magarey, \& Swinburn, 2005). Defining as processed/ultra-processed foods, the industrially produced and ready-to-eat/ready-toprepare are junk foods. Most of the junk foods known to us are ultra-processed foods that substantially include industrial ingredients, additives \& preservatives. Such types of foods include products such as carbonated drinks, sweets, packaged snacks full of fat and salt, chocolate, icecream, processed and packaged bread, cookies, pastries, energy drinks, fruit drinks, instant sauces, many pre-processed ready-to-eat products, and pasta and pizza dishes, burgers, reconstituted meat products, noodles, and desserts (Monteiro, Cannon, Lawrence, Costa, \& Pereira, 2019). Junk food is also defined as food requiring minimum time and effort in preparation and is recognized as convenience/instant eat food (Brunner, Van der Horst, \& Siegrist, 2010).

Age ranging from 10 to 19 years is adolescence as defined by the World Health Organization (WHO). The adolescent stage is the transition stage where health problems and behaviors that may arise affecting physical and cognitive development (WHO, 20I4). Inadequate nutrition may also result in a high risk of chronic disease in adolescents in the future (WHO, 2005). Many adolescents are attracted to unhealthy food practices knowingly or unknowingly. In Nepal, junk foods like samosas, panipuri, chana-chatpatey, potato chips, doughnuts, biscuits, etc. and, sweet beverages/soft drinks like coke, fanta, sprite, pepsi, different juices, and energy drinks are most popular. Fast food items sold in roadside stalls/restaurants/canteen like momo, chowmein, pasta, and packed noodles are junk foods. Such foods contain a high amount of Monosodium Glutamate 
(MSG), a flavor enhancer recognized as a health hazard if taken in larger quantities (Niaz, Zaplatic, \& Spoor, 2018). Most people prefer such types of foods because of their taste. Such foods also contain different preservatives that may be toxic if taken in a large amount. Also, maximum consumption of white flour/ refined flour used in producing various food products and packaged foods leads to serious health issues (Swaminathan et al., 202I). In Nepal, the percentage of households consuming biscuits/cookies is $95.6 \%$ according to the Nepal National Micronutrients Status Survey (NNMSS) 2016 (MOHP et al., 2018), which indicates the consumption of prepacked foods is rapidly increasing in Nepal. A report prepared by the Nepal Health Research Council (Aryal et al., 2016) mentions that according to the Adolescents Nutrition Survey Nepal 2014 conducted to determine the nutritional status of adolescents aged 10-19 years, junk food preference is growing among adolescents. More than $90 \%$ of the adolescents responded that they had recognized the role of nutrition-rich food in their physical and mental development. But their habit was revealed contrary to their understanding. An overwhelming proportion of adolescents consumed junk foods at a frequency of at least twice a week. There is a need for interventions to encourage healthy eating habits in adolescents (Singh, Gautam, Bhandari, \& Sapkota, 2020).

Discussions on the increasing rate of junk food consumption have been prominent nowadays. By developing a nutrient profile model, WHO Regional Office for Europe has not allowed the marketing of foods like confectionery, chocolates, cakes, sweets, biscuits, sugar-laden energy drinks, processed pulp juices, and edible ice. Further, they are also not recommended in the national dietary guidelines (WHO, 2016). A report (United Nations, 2014) released by the United Nations (UN) special rapporteur on "Unhealthy foods, non-communicable diseases and right to health" urged governments to take countermeasures regarding junk foods by documenting food and nutrition guidelines \& regulating marketing as well as advertising of junk food. The government of Nepal formulates food security policies to implement programs related to junk foods and to demoralize the use of such foods. Similarly, the Multi-sectoral Action Plan on the Prevention and Control of Non-communicable Diseases (NCD) in Nepal (2014-2020) planned to reduce consumption of salt, saturated fat, and trans-fat as part of an unhealthy diet (Government of Nepal, 20 I4). Various factors like easy access, taste, appealing advertisements, use of sweetening agents, additives, and food preservatives attract many children and adolescents, and children deny eating homemade foods (Chalise, 2018). Easy availability \& accessibility at doorsteps with expansion in the number of shops and vendors have increased the level of consumption of highly processed and packaged foods (Resource Centre for Primary Health Care, 2016). A cross-sectional survey among Australian children aged $5-16$ years to assess junk food consumption trends and associated characteristics concludes that the unhealthy parenting and home environment measures were associated with high scores on the junk food intake measure. Study shows that children having soft drinks available at home, children eating dinner in front of the TV, children not meeting screen time recommendations at weekends, and children with TV positioned in their bedroom consumed high junk foods (Boylan, Hardy, Drayton, Grunseit, \& Mihrshahi, 2017). Screen time also plays an important role in the activities and behavior of young children (Biddle, Petrolini, \& Pearson, 20I4). Advertising junk food on TV potentially promotes unhealthy food consumption habits among children (Dixon, Scully, Wakefield, White, \& Crawford, 2007). A cross-sectional study (Poudel, Tiraphat, \& Hong, 2018) examined factors associated with junk food practice among urban secondary school students (Grade 6,7 \& 8) of Kathmandu, Nepal. This study showed II.8\% had a 
high level of junk food consumption \& those students obtaining more pocket money, students influenced by parents and peers were more likely to have high junk foods. Unhealthy food practice is due to individual, socio-cultural, poor parenting, influential socioeconomic levels, family characteristics, inappropriate social norms, knowledge deficiency, and self-efficacy (Feyzabadi et al., 2017). Students were aware of the risks inherent with unhealthy eating habits, but they prefer junk food for different reasons like it is faster to prepare, for taste, unavailability of alternatives to eat, influence by advertisements, influence by peers, and so on (Sapkota and Neupane, 20I7).

\section{MATERIALS AND METHODS}

\section{Data and study area}

This research is completely based on the primary (firsthand) data accumulated by the researchers. The study is carried out in Ratnanagar Municipality of Chitwan district of Nepal. As per the information gathered from the record of the municipality education board, the number of registered secondary level schools was 15 government and 18 private schools just before Falgun, 2076 BS (February 2020), the period of data collection. All secondary level students of grades 9 , 10, II \& 12 in the schools of Ratnanagar Municipality comprise the study population. Out of 33 secondary level schools, 9 sample schools including both government and private were selected. Among these 9 schools, 4 were government and 5 were private schools selected using stratified random sampling with proportional allocation method. Out of 2875 students studying in these sampled schools in secondary level, a random sample of 37 I students was included in the study, selected by using proportional allocation with respect to the size of the class. The sample size for the study determined by using the formula given by (Yamane, 1973) was 35I, and considering a $10 \%$ non-response rate, a total of 386 students were planned to be included in the survey, but finally, 37I students were observed at the time of data collection. These sample students were selected randomly with the help of excel using the RANDBETWEEN command by generating the random number of roll numbers of students from respective classes.

The study protocol regarding the research was approved by the Research Committee of the Central Department of Statistics, Tribhuvan University, Kathmandu. A letter of request was submitted to each school selected for the study regarding the permission for data collection. Written informed consent was also taken from each participant, and students were notified about the main motive of the study, the confidentiality of their answers, and they were informed to answer the questions independently without any doubt about the right and wrong answers, before the data collection. The seven-day dietary recall method was used to discover their recent week junk food consumption pattern. The data collection was based on the structured questionnaire developed by the researchers after the literature reviews related to the study topic. Respondents were kept in groups and after the necessary guidelines provided by researchers, questionnaires were filled by students themselves.

\section{Dependent variable}

The dependent variable of the study is Junk food consumption level. In the case of dependent variables, the items are categorized into 4 types, sweets like chocolates/cookies/ biscuits/cakes/jeri/ice-cream/doughnuts, etc. Sweet beverages/soft drinks like coke/fanta/ sprite/juices/red bull etc. and fast foods like samosa/chowmein/momo/burger/pasta/French fries/fried chicken/pizza, etc. and salty snacks like noodles/chana-chatpatey/panipuri/ 
chips/kurkure/lays, etc. The consumption level is determined by asking the students what frequency they ate the above 4 kinds of snacks in previous weeks like a) Never or rarely b) I-2 times per week c) 3-4 times per week d) 5-6 times per week e) I time per day f) $>2$ times per day scoring with $0,1,2,3,4,5$ respectively. Then, the total sum of junk food consumption is computed with a maximum of 20 and a minimum of 0 . Then the junk food consumption scores are categorized into terciles (Boylan et al., 2017) as a) Low consumption (0-7), b) Moderate consumption (8-II), c) High consumption (12-20).

\section{Independent variables}

Different variables were selected after the literature review. Knowledge of junk food consumption was measured with 10 questions consisting of questions relating to an understanding of nutrition, selecting foods following nutritional principles, understanding of types and nutrients of junk foods, advantages and disadvantages of junk foods, and so on. For each question, there were 2 choices, Yes or No. Testing the reliability of knowledge questions, Cronbach alpha was obtained from 10 statements as 0.747 . Knowledge was measured as low level and high level categorized using median cutoff score. Similarly, recognition of the marketing promotion strategies refers to the things that persuaded students to buy junk foods as related to advertising. Students were asked whether marketing strategies influenced their decision-making or not. There were 5 frequency scale questions [adapted from (Liao, Lai, Chang, \& Lee, 2016)]. The score ranges from 0 -20. The Cronbach alpha from 5 statements is 0.737 . Recognition of marketing promotion strategy was measured as having an effect and no effect of marketing categorized using median cutoff value. Also, restrictive food parenting practice refers to the behavior of the guardians that encourage or prohibit them to consume junk foods. Nine 5 points Likert scale questions [adapted from (Kremers et al., 2013)] score ranges from 9-45. The Cronbach alpha for 9 statements is 0.768 $\&$ it was measured as a low and high restriction. Furthermore, attitude towards food choice refers to the perceptions/belief of students towards selecting food as related to the type of food that they should and should not eat and it was measured as low and high attitude. Also, friends' encouragement for junk food consumption refers to the behavior of the friends that encourage them to consume junk foods and is measured as having high and low encouragement. There were four frequency scale questions partially adapted from Apart from the above-mentioned variables, the variables like cost sensitivity, age of a student, gender of a student, religion of a student, type of family, educational level of the student, type of school, average monthly income of a family, students daily pocket money, place of living, educational level of father, educational level of mother, occupation of father, occupation of mother, the reason for junk food consumption, previous awareness about junk foods \& sedentary habit/behavior were also taken as independent variables.

\section{Data analysis}

The research includes both descriptive as well as inferential studies. Descriptive statistics like frequencies, percentage, mean, standard deviation, minimum, maximum, bivariate analysis using Chi-square test, Fisher's exact test, and bivariate multinomial regression, etc. were used for the data analysis as per need and according to the nature of variables. For model fitting to determine the significant factors which contribute towards junk food consumption, which is ordinal firstly, an ordinal logistic regression model (OLRM) was used and likelihood ratio test implies that test of parallel lines in OLRM was violated. Due to the violation of the assumption of an OLRM, an 
alternative model called MLRM is considered by taking the junk food consumption with three categories low, moderate \& high consumption as dependent variable and significant variables from bivariate analysis as regressors/predictors. Firstly, validity of the fitted model was assessed by the application of different tests like model adequacy tests and summary measure of goodness of fit tests and later MLRM was used after the verification of the validity of the model. In the threeoutcome category model, we require two logit functions. In this research low consumption is taken as a reference category, hence, would take odds of low versus moderate \& low versus high. Here the three categories are coded as $Y=I, 2$, and 3 . The reference category is chosen first and suppose this is the category $Y=1$. Then the logits for other categories are defined by comparing $Y=2$ and $Y=3$ with $Y=1$. To develop the model, we assume there are $p$ covariates.

$$
\text { Logit }\left(\pi_{i j}\right)=\ln \frac{\pi_{i j}}{\pi_{i 1}}=X_{i j}^{T} \beta_{j} \text {, for } j=2,3
$$

where, $\pi_{i j}$ is the probability representation of $\mathrm{i}$-th response falling in the $\mathrm{j}$-th category, $\pi_{i j}=$ $\operatorname{Pr}\left\{Y_{i}=j\right\} ; j=2,3$ The $(-I)$ logit equations are used simultaneously to estimate the parameters $\beta_{j}$. Once the parameter estimates $b_{j}$, have been obtained, the linear predictors $X_{i j}^{T} b_{j}$, can be calculated, where, $X_{i j}^{T} b_{j}=\alpha_{j}+\sum_{p=1}^{m} \beta_{j p} X_{p}, \alpha_{j}$ is a constant, $\beta_{j p}$, is the regression coefficient for $j=2,3$ and $X_{p}(p=l, 2 \ldots m)$ are explanatory variables.

$\hat{\pi}_{i j}=\hat{\pi}_{i 1} \exp \left(X_{i j}^{T} \beta_{j}\right)$ for $j=2,3$

With the assumption of response categories being mutually exclusive, we can write,

$\sum \hat{\pi}_{i j}=1$, and $\hat{\pi}_{i j}=\frac{\exp \left(\mathrm{x}_{\mathrm{ij}}^{\mathrm{T}} \mathrm{b}_{\mathrm{j}}\right)}{1+\sum_{j=2}^{3} \exp \left(\mathrm{x}_{\mathrm{ij}}^{\mathrm{T}} \mathrm{b}_{\mathrm{j}}\right)}$, for $j=2,3$

The parameters of the model are estimated based on the maximum likelihood estimation method which follows the Newton-Raphson iteration process (McCullagh \& Nelder, 1989).

\section{RESULTS}

The study shows that $33.7 \%$ of the students had low junk food consumption level in the previous week, $36.9 \%$ of the students had moderate consumption of junk foods and $29.4 \%$ had a high consumption of junk foods in the previous week (Table I).

Table I. Frequency distribution of Junk food consumption level.

\begin{tabular}{lcc}
\hline Junk food Consumption level & Frequency & Percentage \\
\hline Low consumption of junk foods & 125 & 33.7 \\
\hline Moderate consumption of junk foods & 137 & 36.9 \\
\hline High consumption of junk foods & 109 & 29.4 \\
\hline Total & 371 & 100 \\
\hline
\end{tabular}

Table 2 comprises the distribution of study variables like demographic, socio-economic, and other variables. The study shows that $50.4 \%$ of respondents were female and the rest of all were male. The study consists of most of the respondents $(68.7 \%)$ from nuclear families. The findings show that the study participants consisted of $85.7 \%$ Hindu, and the rest were non-Hindu. Similarly, the study consists of $23.7 \%, 22.1 \%, 24.5 \%, \& 29.6 \%$ respectively from level $9,10,11$ \& 12 . Next, $59.8 \%$ of the students were from government schools \& $40.2 \%$ were from private schools. Similarly, most of the students ( $91.6 \%$ ) used to stay at their own homes. Most of the respondents' fathers' 
education \& mothers' education was secondary level (9-12). Fathers were mainly farmers/daily laborers (29.9\%), and mothers were housewives (71.4\%). Students preferred junk food mostly for taste $(52.0 \%)$ and as an alternative to breakfast (31.5\%).

Most of the students (97.3\%) said that they had received previous education regarding junk foods either formally or informally. Sedentary behavior was assessed by inquiring about their average usage of mobile phones and watching TV in a day, of which $42.9 \%$ of the students reported that they spend $>2$ hours on sedentary behavior. Some respondents even agree (19.7\%) that junk foods being less expensive they eat mostly. Moreover, $34.5 \%$ of the respondents had a low level of knowledge regarding junk foods, $59.8 \%$ of the respondents had a low/negative attitude about food choices, $7.5 \%$ of the respondents reported high encouragement of their friends for unhealthy eating, and $86.8 \%$ of the respondents had low restrictive food parenting practices. Additionally, $50.9 \%$ of the respondents had the effect of marketing promotion strategy on the consumption of junk foods. The mean age of students at the time of data collection was 16 years with a minimum of 13 \& a maximum of 18 years, respectively. The mean daily pocket money was about 52 rupees with a minimum of 10 rupees and a maximum of 300 rupees. The average family income reported by students is 47699 rupees with minimum and maximum 3600 and 250000 rupees, respectively.

Table 2. Frequency distribution of background characteristics of students under study $(n=37 \mathrm{I})$.

\begin{tabular}{|c|c|c|c|c|}
\hline Factors & Variables & Categories & Frequency & Percent \\
\hline \multirow{14}{*}{$\begin{array}{c}\text { Demograp } \\
\text { hic } \\
\text { Variables }\end{array}$} & \multirow{2}{*}{ Gender } & Male & 184 & 49.6 \\
\hline & & Female & 187 & 50.4 \\
\hline & \multirow{2}{*}{ Type of Family } & Nuclear & 255 & 68.7 \\
\hline & & Joint/Extended & 116 & 31.3 \\
\hline & \multirow{2}{*}{ Religion } & Hindu & 318 & 85.7 \\
\hline & & Non-Hindu & 53 & 14.3 \\
\hline & \multirow{4}{*}{$\begin{array}{l}\text { Educational level of } \\
\text { student }\end{array}$} & 9 & 88 & 23.7 \\
\hline & & 10 & 82 & 22.1 \\
\hline & & II & 91 & 24.5 \\
\hline & & 12 & 110 & 29.6 \\
\hline & \multirow{2}{*}{ Type of School } & Government & 222 & 59.8 \\
\hline & & Private & 149 & 40.2 \\
\hline & \multirow{2}{*}{ Place of Living } & Home & 340 & 91.6 \\
\hline & & Other (Hostel/Rent/Relatives) & 31 & 8.4 \\
\hline \multirow{9}{*}{$\begin{array}{l}\text { Socio- } \\
\text { economic } \\
\text { Variables }\end{array}$} & \multirow{5}{*}{$\begin{array}{l}\text { Educational level of } \\
\text { Father }\end{array}$} & Illiterate & 17 & 4.6 \\
\hline & & Literate \& primary level & 84 & 22.6 \\
\hline & & Lower secondary level (6-8) & 69 & 18.6 \\
\hline & & Secondary level $(9-12)$ & 158 & 42.6 \\
\hline & & Bachelors \& above & 43 & 11.6 \\
\hline & \multirow{4}{*}{$\begin{array}{l}\text { Educational level of } \\
\text { Mother }\end{array}$} & Illiterate & 29 & 7.8 \\
\hline & & Literate \& primary level & 93 & 25.1 \\
\hline & & Lower secondary level (6-8) & 82 & 22.1 \\
\hline & & Secondary level $(9-12)$ & $|5|$ & 40.7 \\
\hline
\end{tabular}




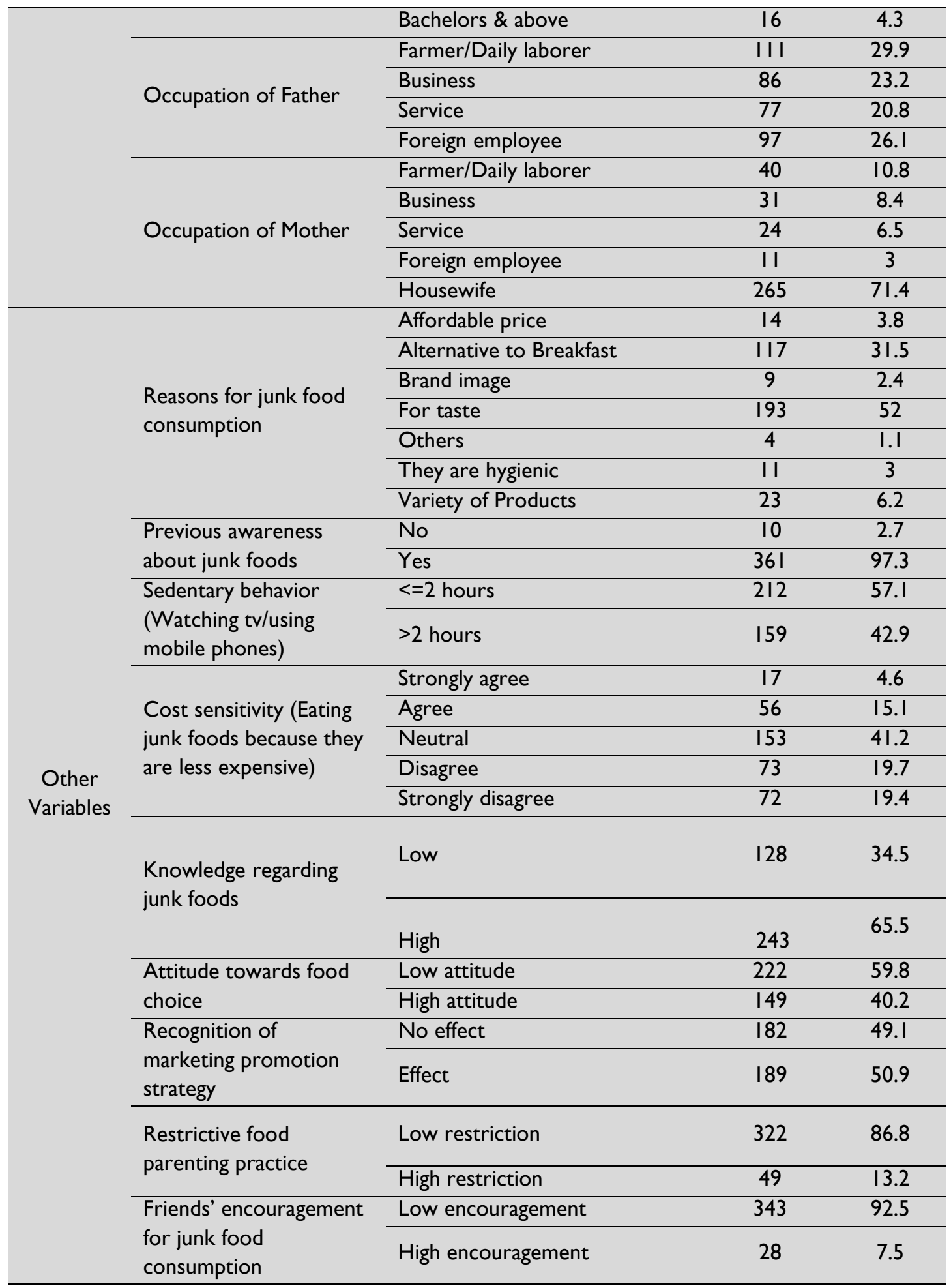




\section{Bivariate analysis}

Family monthly income $(p$-value $<0.10)$ shows significant effect in junk food consumption level which is tested using bivariate multinomial logistic regression. Similarly, students' daily pocket money ( $p$-value $<0.00 \mathrm{I}$ ) shows significant effect in junk food consumption level using bivariate multinomial logistic regression. From the comparison of junk food consumption level among the respondents with different categorical variables separately, gender $(p-v a l u e=0.062)$, type of school $(p-v a l u e=0.063)$, educational level of mother $(p-v a l u e=0.012)$, occupation of father ( $p$-value $=$ $0.03 \mathrm{I}$ ), sedentary behavior ( $(p$-value $=0.007)$, cost-sensitivity $(p$-value $=0.032)$, knowledge regarding junk foods ( $p$-value $=0.009)$, attitude towards food choice $(p$-value $=0.00 \mathrm{I})$, friends' encouragement for junk food consumption ( $p$-value $=0.047)$, restrictive food parenting practice $(p$-value $=0.063)$, recognition of marketing promotion strategy $(p$-value $=0.012)$ were found significantly associated with the junk food consumption level at $10 \%$ level of significance using bivariate analysis of Chisquare test which is performed using cross-tabulation method. Further, significant variables from bivariate analysis were included in the MLRM and non-significant variables were excluded from the final MLRM model. Firstly, the OLRM had been tried to fit by taking Junk food Consumption level having three categories- Low, Moderate \& High Consumption as the dependent variable and significant variables from bivariate analysis as predictors/regressors. The violation of the assumption of proportional odds which is tested by a test of parallel lines resulted that an alternative model called the MLRM is considered by taking the junk food consumption with three categories low, moderate $\&$ high consumption as the dependent variable and significant variables from bivariate analysis as regressors.

Table 3 comprises the estimates of MLRM coefficients, $\mathrm{p}$-value, and odds ratios for each category. From the fitted MNLR model, variables like family monthly income, students daily pocket money, gender, knowledge regarding junk foods, attitudes towards food choice, friends' encouragement for junk food consumption \& occupation of the father (business) are significant to the model high versus low consumption. Similarly, students' daily pocket money, knowledge regarding junk foods, restrictive food parenting practice, friends' encouragement for junk food consumption, recognition of marketing promotion strategy, educational level of mother (lower secondary level) \& occupation of father (business) are significant to the model moderate versus low consumption. The odds ratio is $1.00001 \mathrm{I}$ for the family monthly income for the model high versus low, which means that each additional increment of monthly income by lakhs results in a $1.1 \%$ increase in the odds of high versus low consumption. But it did not show a significant effect for the model moderate versus low consumption. Similarly, the odds ratio of students' daily pocket money is 1.020 for the model high versus low \& 1.012 for the model moderate versus low consumption. It reveals that each additional 100 rupees in students' daily pocket money result in a $2 \% \& 1.2 \%$ increase in the odds of high versus low \& moderate versus low junk food consumption, respectively. The odds ratio of low attitude towards food choices is 2.487 for the model high versus low consumption. It indicates that students with negative/low attitudes about food choices are 2.487 times more likely to have high junk food consumption relative to low compared to those with a high/positive attitude. There is no significant effect of attitude in the case of moderate versus low consumption of junk foods. Furthermore, the odds ratio of males compared to females is 0.354 . It indicates that male students have a 65 percent less chance of having high junk food relative to low junk food compared to female students. Likewise, the odds ratio of a low level of knowledge 

towards junk food consumption as compared to a high level of knowledge is 2.427 \& 2.744 for moderate relative to low $\&$ high relative to low consumption, respectively. This indicates that the students with a low level of knowledge are 2.427 times \& 2.744 times more likely to have moderate consumption relative to low consumption \& high relative to low consumption respectively, compared to the students with a high level of knowledge. The odds ratio of no effect of recognition of marketing promotion strategy on junk food consumption as compared to the effect of recognition of marketing promotion strategy is 0.523 . It indicates that the students having no effect of marketing promotion strategy have $48 \%$ less chance of having moderate consumption relative to low consumption as compared to the students who said that there is the effect of marketing strategy on junk food consumption. There is no significant effect of recognition of marketing promotion strategy on model high versus low.

The odds ratio of low restriction of parents compared to high restriction of parents is 2.228 . It indicates that the students with low restriction of parents are 2.228 times more likely to have moderate consumption relative to low consumption compared to the students with high restriction of parents towards junk food consumption. But there is no significant effect of parents' restriction towards high versus low junk food consumption. The odds ratio of low encouragement of friends towards junk food consumption as compared to high encouragement of friends is 0.252 which indicates that the students with low encouragement of friends have $75 \%$ less chance of having moderate consumption relative to low consumption as compared to those with high encouragement of friends. Similarly, the odds ratio of low encouragement of friends towards junk food consumption as compared to high is 0.178 . It indicates that the students with low encouragement of friends have $82 \%$ less chance of having high consumption relative to low consumption as compared to the students with high encouragement of friends. The odds ratio of the educational level of mothers with lower secondary level compared to bachelors and above is 5.465 which indicates that the students whose mothers are less educated are more likely to have moderate versus low consumption. But there is no significant effect of mother education in model high versus low consumption. The odds ratio of father occupation as a business compared to a foreign employee is $2.470 \& 2.867$ respectively for moderate versus low and high versus low consumption which indicates that the students whose father's earning are maximum, they are more likely to have junk foods.

\section{Model adequacy test}

In the logistic regression model, the likelihood ratio test is based on the $-2 L L$ value. The likelihood ratio test is the test of significance using the Chi-square test, where the difference between the baseline model (intercept only) and the final model (a model after all the regressors are incorporated) is computed. In this research, the $-2 \mathrm{LL}$ value for a baseline model is 802.826 and the final $-2 \mathrm{LL}$ value is 685.386 . The difference between these two measures following a chi-square distribution tells us about how preciously the regressors affect the outcome variable. This research result ( $p$-value $<0.00 \mathrm{I}$ ) reveals that at least one and perhaps most of the coefficient is different from zero and indicates that all the regressors have a significant contribution to predict the junk food consumption level. The Chi-square test seems to be significant for the fitted model which manifests that the model fitting is acceptable. Similarly, the predictive accuracy of the MNLR is assessed by examining classification accuracy value, which is a benchmark model and that will be used to characterize the MNLR model as useful is a $25 \%$ improvement over the rate of accuracy achievable 
by chance alone. In this study, the proportional by chance accuracy rate is $42.03 \%$ and the classification accuracy rate is $55.0 \%$ which is greater than chance accuracy, implying the satisfaction of classification accuracy. Further, the predictive power of the fitted model is explained by examining the pseudo $R^{2}$ value, where pseudo $R^{2}$ measures the proportion of variation in the categories of junk food consumption level of students that can be explained by the predictors/regressors in the model. Here, Nagelkerke $R^{2}$ is found to be 0.306 , indicating that about $31 \%$ of the variation in the categories of junk food consumption level is explained by predictors in the model. The Variance Inflation Factor (VIF) of all covariates was less than 2. Calculated values of VIF indicate that the assumption of multicollinearity is satisfied. It indicates that there is no multicollinearity between the covariates.

\section{Summary measure of goodness of fit}

The Deviance and Pearson's $\chi^{2}$-test is useful in testing the overall goodness of fit of the estimated model. From the research result, it is seen that non-significant Pearson's and Deviance Chi-square statistics with $p$-value 0.413 and 0.570 , respectively suggest that MLRM adequately fits the data. The multinomial model can be observed as if it were a set of independent binary logistic regression models considering each outcome against the reference outcome and testing the goodness-of-fit of each of these separately (Hosmer and Lemeshow, 2000). Hosmer \& Lemeshow chi-square goodness-of-fit tests for both the logits with high $\mathrm{p}$-values revealed that model performance is excellent. While examining the validity of the fitted model, the value of chi-square from the Hosmer \& Lemeshow test for both the models are II.464 for low versus moderate \& 6.847 for low versus high with their $\mathrm{p}$-values $0.177 \& 0.553$ respectively, which are greater than 0.1 . It shows that there is no such significant difference in observed \& expected number for both groups low versus moderate $\&$ low versus high. It means that the fitted model is valid at a $10 \%$ level of significance. Generally, the Hosmer \& Lemeshow chi-square test contains 8 degrees of freedom (Hosmer and Lemeshow, 2000) which is also satisfied in this model fit.

\section{DISCUSSION}

More than one-fourth of the respondents had high junk food consumption level. Research results shows that there is a significant difference between adolescents in junk food consumption level regarding gender implying that females consumed more junk foods than males. In contrast to this, most of the studies conducted have found high consumption by males as in the study by Feyzabadi et al. (2017) where 8th-grade students of age 14 years were taken as a sampling frame and in that study compared with females, males were associated with higher weekly unhealthy snacking. The same study by Feyzabadi et al. (2017) is consistent with the findings of this study on socio-economic status regarding family monthly income where the study on high socio-economic status was associated with higher weekly unhealthy snacking compared with the low socioeconomic status. This may be because people with high socioeconomic status can provide freedom to their children in spending money on foods that they wish which ultimately results in high consumption of foods preferred by children. In contrast to this finding, a conclusion was obtained (Darmon and Drewnowski, 2008) that low-income groups frequently have poorer diets 
Table 3. Fitted model explaining junk food consumption level.

\begin{tabular}{|c|c|c|c|c|c|c|c|c|}
\hline \multirow[b]{2}{*}{ Variable } & \multicolumn{4}{|c|}{ Moderate Versus Low Consumption } & \multicolumn{4}{|c|}{ High Versus Low Consumption } \\
\hline & $\begin{array}{l}\text { Estimated } \\
\text { Coefficient }\end{array}$ & $\mathrm{p}$-value & $\begin{array}{l}\text { Odds } \\
\text { Ratio } \\
\left(e^{\beta}\right)\end{array}$ & $\begin{array}{l}95 \% \mathrm{Cl} \\
\text { of OR }\end{array}$ & $\begin{array}{l}\text { Estimated } \\
\text { Coefficient }\end{array}$ & $\begin{array}{c}\mathrm{P}- \\
\text { value }\end{array}$ & $\begin{array}{l}\text { Odds } \\
\text { Ratio } \\
\left(e^{\beta}\right)\end{array}$ & $\begin{array}{l}95 \% \mathrm{Cl} \\
\text { of OR }\end{array}$ \\
\hline Family monthly income & $-3.56 * 10^{-6}$ & 0.503 & 0.99999 & $0.99998-1$ & $1.1 * 10^{-5}$ & $0.019 *$ & $1.00001 \mathrm{I}$ & $\begin{array}{l}1.000001- \\
1.00002\end{array}$ \\
\hline $\begin{array}{l}\text { Students Daily Pocket } \\
\text { Money }\end{array}$ & 0.012 & $0.025 *$ & 1.012 & $1.002-1.023$ & 0.02 & $0.002 *$ & 1.02 & $1.007-1.033$ \\
\hline $\begin{array}{l}\text { Attitude towards food } \\
\text { choices (High attitude } \\
\text { () }\end{array}$ & & & & & & & & \\
\hline Low attitude & 0.427 & 0.152 & 1.532 & $0.855-2.745$ & 0.911 & $0.007^{*}$ & 2.487 & $1.288-4.803$ \\
\hline Gender (Female $®)$ & & & & & & & & \\
\hline Gender $=$ Male & -0.503 & 0.101 & 0.605 & $0.332-1.102$ & -1.04 & $0.003^{*}$ & 0.354 & $0.179-0.7$ \\
\hline $\begin{array}{l}\text { Knowledge regarding } \\
\text { junk food (High level of } \\
\text { Knowledge }(\text { ) })\end{array}$ & & & & & & & & \\
\hline $\begin{array}{l}\text { Low level of } \\
\text { Knowledge }\end{array}$ & 0.886 & $0.006 *$ & 2.427 & $1.293-4.553$ & 1.009 & $0.005^{*}$ & 2.744 & $|.366-5.51|$ \\
\hline $\begin{array}{l}\text { Recognition of } \\
\text { marketing promotion } \\
\text { strategy (Effect } \circledR)\end{array}$ & & & & & & & & \\
\hline No Effect & -0.648 & $0.027 *$ & 0.523 & $0.295-0.928$ & -0.265 & 0.418 & 0.767 & $0.404-1.456$ \\
\hline $\begin{array}{l}\text { Restrictive food } \\
\text { parenting practice= } \\
\text { (High restriction } ®)\end{array}$ & & & & & & & & \\
\hline Low restriction & 0.801 & $0.067^{* *}$ & 2.228 & $0.945-5.253$ & 0.008 & 0.985 & 1.008 & $0.422-2.407$ \\
\hline
\end{tabular}




\begin{tabular}{|c|c|c|c|c|c|c|c|c|}
\hline \multicolumn{9}{|l|}{$\begin{array}{l}\text { Friends' } \\
\text { encouragement } \\
\text { (High encouragement } \\
\circledR \text { ) }\end{array}$} \\
\hline Low Encouragement & -1.38 & $0.04 I^{*}$ & 0.252 & $0.067-0.944$ & -1.726 & $0.014^{*}$ & 0.178 & $0.045-0.701$ \\
\hline \multicolumn{9}{|l|}{$\begin{array}{l}\text { Educational level of } \\
\text { Mother (Bachelors \& } \\
\text { above }(\text { ) })\end{array}$} \\
\hline $\begin{array}{l}\text { Illiterate (cannot read } \\
\text { \& write) }\end{array}$ & 0.009 & 0.992 & 1.009 & $0.155-6.576$ & 0.396 & 0.694 & 1.486 & $0.206-10.727$ \\
\hline Literate \& Primary level & 0.207 & 0.806 & 1.23 & $0.236-6.415$ & 0.58 & 0.513 & 1.786 & $0.314-10.169$ \\
\hline $\begin{array}{l}\text { Lower secondary (6- } \\
\text { 8) }\end{array}$ & 1.698 & $0.041 *$ & 5.465 & $1.069-27.952$ & 1.2 & 0.184 & 3.321 & $0.565-19.529$ \\
\hline Secondary level (9-12) & 0.399 & 0.613 & 1.491 & $0.317-7.008$ & 0.226 & 0.786 & 1.254 & $0.244-6.434$ \\
\hline \multicolumn{9}{|l|}{$\begin{array}{l}\text { Occupation of Father } \\
\text { (Foreign employee } \AA \text { ) }\end{array}$} \\
\hline Farmer/Daily Laborer & $-0.34 I$ & 0.423 & $0.7 I I$ & $0.308-1.64$ & 0.609 & 0.226 & 1.839 & $0.686-4.928$ \\
\hline Business & 0.904 & $0.037^{*}$ & 2.47 & $1.056-5.777$ & 1.053 & $0.034^{*}$ & 2.867 & $|.084-7.58|$ \\
\hline Service & 0.057 & 0.894 & 1.059 & $0.456-2.459$ & 0.666 & 0.163 & 1.947 & $0.763-4.966$ \\
\hline
\end{tabular}

( ) denotes reference category, ${ }^{*}=\mathrm{p}-$ value $<0.05,{ }^{* *}=\mathrm{p}$-value $<0.10, \mathrm{~N}=37 \mathrm{I}$ 
than the more affluent, as economically challenged people do not perceive healthy foods like fresh fruit and vegetables may be unaffordable for them which ultimately discourage their consumption.

The result on students' daily pocket money is consistent with the study from Feyzabadi et al. (2017) \& Poudel et al. (2018). The result from this study on knowledge regarding junk foods is consistent with the findings of the study by Fitzgerald, Heary, Kelly, Nixon, \& Shevlin (2013) where the participants of age 13-18 years were recruited, and it was found that higher knowledge regarding nutrition resulted low consumption of unhealthy foods. Advertising of foods in television and modern concept of digital marketing was associated with unhealthy snack consumption in a study conducted in Australia among students of 12-17 years by Scully et al. (2012), which is consistent with our study regarding the recognition of the marketing promotion strategy where the students who said they have the effect of marketing strategy on their purchasing behavior have high junk food consumption. Among many marketing strategies, extravagant health claims advertising by junk food manufacturers are very sensitive and that they try to persuade the consumers like small children and young adolescents to promote their products. Easy access to unhealthy snacks at home and less parental control results in higher unhealthy consumption like junk foods, and this verity is compatible with the findings of the study by Campbell et al. (2007). In that study it was found that unhealthy foods being available at home \& less parental control was positively associated with unhealthy food consumption behavior among adolescents. Also, a study (Kremers et al., 2013) found that healthy food practices by parents ultimately results in healthy dietary intake in children. Children are particularly dependent on others, such as parents or schools, for food, otherwise, they are also more susceptible to marketing pressures. Children are frequently at risk of being exposed to junk foods in both public and private places. Food served or sold in institutions such as schools may be readily available/ready to eat foods that are likely to be junk foods or other foods of limited nutritional value (United Nations, 20l4).

Regarding attitude towards junk food consumption, a study (Vardanjani, Reisi, Javadzade, Pour \& Tavassoli, 2015) shows that there is an effect of students' attitude on their junk food consumption behavior and our study is consistent with those findings regarding the attitude of students towards junk foods. An increase in the positive attitude towards the food choice has been linked with increase in the level of understanding about junk foods which helped to increase the level of knowledge and prevent the high consumption of junk foods (Singh et.al., 2020). The current study shows that friends support for junk foods eating was associated with high junk food consumption level. And this result is consistent with the results from Poudel et al. (2018) and Fitzgerald et al. (2013). A study (Van Ansem, Schrijvers, Rodenburg, \& Van de Mheen, 2014) revealed that children having high educational level of mother have healthy eating behavior. Our study also shows that students whose mothers are educated they have low junk food consumption. A study in India (Arzi, Faizi, \& Chatterjee, 2017) has revealed that driving up junk food demand are several stronger variables embedded and which also consists of father's occupation and our study also shows that father occupation (business) is significant towards junk food consumption.

\section{CONCLUSION}

The result from the study has concluded that the proportion of junk food consumption is increasing rapidly among school-going adolescents. It is seen that various variables like family 
monthly income, students' daily pocket money, gender, knowledge regarding junk foods, attitudes towards food choices, restrictive food parenting practice, friends' encouragement for junk food consumption, the effect of marketing strategy, parents' education seems to be significant in explaining the factors that are associated with increased consumption of unhealthy foods like junk foods. Regardless of having adequate knowledge about the impact of junk foods on health, adolescents are consuming them frequently due to various reasons like easily accessible, convenient to use, for taste, as an alternative to breakfast, and so on. Having a low attitude or negative perception about food choices, media exposure, and getting persuaded by advertisements like the branded image or outer attire of any products and many other factors have challenged the issue. Family and friends' roles are also found to be more crucial in increased consumption among adolescents. Trying to address the issue of influencing factors through different programs \& developing strategies to change the behavior of the people towards adopting healthy eating habits, including research on food that is supplied and demand for food varieties is mostly important. Especially the government plan and policies are vital for the continuation of any programs. Thus, regarding this issue, responsible authorities should run programs related to child and young student's health, awareness programs, programs related to food hygiene can be advantageous. Local communities, schools, food companies, and every responsible person and organization should partner in promoting healthy food choices. The government should encourage advertisements of healthy food and extravagant health claims advertised by food manufacturers should be stopped.

\section{CONFLICT OF INTEREST}

The authors declare that they have no conflict of interest.

\section{ACKNOWLEDGEMENTS}

The authors would like to express their sincere appreciation to all the respondents who have participated in the survey providing valuable information. The authors would also like to thank Prof. Dr. Shankar Prasad Khanal and Prof. Dr. Azaya Bikram Sthapit for providing reasonable comments in completing this work. Appreciation also goes to Mr. Ananda Subedi for his assistance during the study period.

\section{REFERENCES}

Aryal, K. K., Mehta, R. K., Chalise, B., Mehata, S., Sapkota, F., Dhimal, M...\& Karki, K. B. (2016). Adolescent Nutrition Survey in Nepal 2014. Kathmandu, Nepal: Nepal Health Research Council.

Arzi, A., Faizi, N., \& Chatterjee, C. (2017). Analyzing the lazy mother argument inspired by the Maggi controversy evidence from junk food intake in India. Economic and political weekly, 52(28). Retrieved from: https://www.epw.in/journal/2017/27/specialarticles/analysing-lazy-mother-argument-inspired-maggi-controversy.html

Bell, A. C., Kremer, P. J., Magarey, A. M. \& Swinburn, B. A. (2005). Contribution of noncore foods and beverages to the energy intake and weight status of Australian children. European Journal of Clinical Nutrition, 59(5), 639-645.

Biddle, S. J., Petrolini, I., \& Pearson, N. (20I4). Interventions designed to reduce sedentary behaviors in young people: a review of reviews. Br J Sports Med, 48(3), 182-186. 
doi: https://doi.org/10.1 136/bjsports-2013-093078

Boylan, S., Hardy, L. L., Drayton, B.A., Grunseit, A., \& Mihrshahi, S. (2017). Assessing junk food consumption among Australian children: trends and associated characteristics from a cross-sectional study. BMC Public Health, 17, 299. https://doi.org/10.1 I86/s I 2889-0I74207-x

Brunner, T. A., Van der Horst, K. \& Siegrist, M. (2010). Convenience food products. Drivers for consumption. Appetite, 55(3), 498-506. doi: https://doi.org/10.1016/j.appet.2010.08.017

Campbell, K. J., Crawford, D. A., Salmon, J., Carver, A., Garnett, S. P., \& Baur, L. A. (2007). Associations between the home food environment and obesity promoting eating behaviors in adolescence. Obesity (Silver Spring, Md.), 15(3), 719-730. doi: https://doi.org/10.1038/oby.2007.553

Chalise, B. (2018). Junk food prevention education package intervention and its effect on behavioral intention among students of Kageswori Manohara Municipality, Kathmandu district, Nepal. MOJ Public Health, 7(3), 123-127.

doi: https://doi.org//0.15406/mojph.2018.07.002I7

Darmon, N., \& Drewnowski, A. (2008). Does social class predict diet quality?. American Journal of Clinical Nutrition, 87(5), II07-III7

Dixon, H. G., Scully, M. L., Wakefield, M. A., White, V. M., \& Crawford, D. A. (2007). The effects of television advertisements for junk food versus nutritious food on children's food attitudes and preferences. Soc Sci Med, 65(7), I 3 I I-1323.

doi: https://doi.org/10.1016/j.socscimed.2007.05.01 I

Feyzabadi, V. Y., Mohammadi, N. K., Omidvar, N., Karimi- Shahanjarini, A., Nedjat, S., \& Rashidian, A. (2017). Factors Associated with Unhealthy Snacks Consumption Among Adolescents in Iran's Schools. Int J Health Policy Manag, 6(9), 519-528.

doi: https://doi.org/10.15171/ijhpm.2017.09

Fitzgerald, A., Heary, C., Kelly, C., Nixon, E., \& Shevlin, M. (20I3). Self-efficacy for healthy eating and peer support for unhealthy eating are associated with adolescents' food intake patterns. Appetite, 63, 48-58. https://doi.org/10.1016/j.appet.2012.12.0II

Food and Agricultural Organization/World Health Organization (2003). Diet, nutrition and the prevention of chronic diseases: Report of a Joint FAO/WHO Expert Consultation. WHO Technical Report Series No. 916. Geneva, Switzerland. Available at: https://www.who.int/dietphysicalactivity/publications/trs9/6/download/en/

Government of Nepal. (2014). Multisectoral Action Plan for the Prevention and Control of Non-Communicable Diseases (2014-2020). Kathmandu, Nepal.

Hadjikakou, M., \& Baker, P. (2017). The untenable role of "junk food" in a healthy and sustainable food system. In Lawrence, M. \& Friel, S. (Eds.), Healthy and Sustainable Food Systems (pp. 158- 169). London: Routledge. Retrieved from URL:https://www.taylorfrancis.com/books/e/978 I 35 I I89033/chapters/ 10.4324/978 | 35 I 189033-14

Hosmer, D. W., \& Lemeshow, S. (2000). Applied logistic regression (2nd ed.). John Wiley \& Sons, Inc, New York.

Kremers, S., Sleddens, E., Gerards, S., Gubbels, J., Rodenburg, G., Gevers, D., \& Assema, P. V. (20I3). General \& Food-specific Parenting: Measures and interplay. Childhood Obesity, 9(I). doi: https://doi.org//0.1089/chi.2013.0026 
Liao, L. L., Lai, I. J., Chang, L. C., \& Lee, C. K. (2016). Effects of a food advertising Literacy intervention on Taiwanese children's food purchasing behaviors. Health Education Research. 31 (4). 509-520. doi: https://doi.org/10.1093/her/cyw025

McCullagh, P., \& Nelder, J. A. (1989). Generalized Linear Models (2nd ed.). Chapman \& Hall, London.

Ministry of Health and Population, Nepal; New ERA; UNICEF; EU; USAID; \& CDC. (2018). Nepal National Micronutrient Status Survey, 2016. Kathmandu, Nepal. Ministry of Health and Population, Nepal. Retrieved from: NNMSS Report 2016.pdf (unicef.org)

Monteiro, C. A., Cannon, G., Lawrence, M., Costa Louzada, M. L. \& Pereira Machado, P. (2019). Ultra-processed foods, diet quality, and health using the NOVA classification system. Rome, FAO.

Niaz, K., Zaplatic, E., \& Spoor, J. (2018). Extensive use of monosodium glutamate: A threat to public health? EXCL/ journal, 17, 273-278. doi: https://doi.org//0.17/79/excli2018-1092

Poudel, B., Tiraphat, S., \& Hong, S. A. (2018). Factors associated with junk food consumption among urban school students in Kathmandu District of Nepal. J

Pub Health Dev, I6(2), 59-72.

Resource Centre for Primary Health Care. (2016). Food Environment of Kathmandu Metropolitan area. Kathmandu, Nepal.

Sapkota, S. D., \& Neupane, S. (2017). Junk Food Consumption Among Secondary Level Students, Chitwan. J Nepal Paediatr Soc, 37(2), I47-I52. doi: http://dx.doi.org//0.3 I26/jnps.v37i2.1708।

Scully, M., Wakefield, M., Niven, P., Chapman, K., Crawford, D., Pratt, I. S., Baur, L. A., Flood, V., Morley, B., \& NaSSDA Study Team. (2012). Association between food marketing exposure and adolescents' food choices and eating behaviors. Appetite,58(I), I-5. doi: https://doi.org/10.1016/j.appet.2011.09.020

Singh, U. K., Gautam, N., Bhandari, T. R., Sapkota, N. (2020). "Educational Intervention of Intention Change for Consumption of Junk Food among School Adolescents in Birgunj Metropolitan City, Nepal, Based on Theory of Planned Behaviors". Journal of Nutrition and Metabolism. Vol. 2020. doi: https://doi.org// 0.I I55/2020/7932324

Stedman, T. L. (2012). Stedman's medical dictionary for the health professions and nursing. Philadelphia: Wolters Kluwer Health/Lippincott Williams \& Wilkins

Swaminathan, S., Dehghan, M., Raj, J. M., Thomas, T., Rangarajan, S., Jenkins, D. et al. (202I). Associations of cereal grains intake with cardiovascular disease and mortality across 21 countries in prospective urban and rural epidemiology study: prospective cohort study. BMJ. doi: https://doi.org//0.1 136/bmj.m4948

United Nations (2014). Report of the Special Rapporteur on the Right of Everyone to the Enjoyment of the Highest Attainable Standard of Physical and Mental Health, Anand Grover: unhealthy foods, non-communicable diseases and the right to health. Human Rights Council. Retrieved from: https://digitallibrary.un.org/record/77/865

Van Ansem, W. J., Schrijvers, C. T., Rodenburg, G., \& van de Mheen, D. (2014). Maternal educational level and children's healthy eating behaviour: role of the home food environment (cross-sectional results from the INPACT study). The international journal of behavioral nutrition and physical activity, II, II3. doi: https://doi.org/| 0.1 I86/s/2966-014-0| I3-0 
Vardanjani, A. E., Reisi, M., Javadzade, H., Pour, Z. G., \& Tavassoli, E. (20I5). The Effect of nutrition education on knowledge, attitude, and performance about junk food consumption among students of female primary schools. Journal of education and health promotion, 4, 53. doi: https://doi.org/10.4103/2277-9531.162349

World Health Organization (2005). Nutrition in Adolescence: Issues and Challenges for the Health Sector: Issues in Adolescent Health and Development. World Health Organization.

World Health Organization (2014). Health for the world's adolescents. Available at: www.who.int/adolescent/second-decade

World Health Organization (2016). Tackling food marketing to children in a digital world: trans-disciplinary perspectives. Available at: https://www.euro.who.int/en/healthtopics/disease-prevention/nutrition/publications/20l6/tackling-food-marketing-tochildren-in-a-digital-world-trans-disciplinary-perspectives.-childrens-rights,-evidence-ofimpact,-methodological-challenges,-regulatory-options-and-policy-implications-for-thewho-european-region-2016

Yamane, T. (1973). Statistics: An Introductory Analysis (3rd ed.). Harper and Row, New York.

Reference to this paper should be made as follows:

Subedi, S., \& Bhusal, M. K. (202I). Multinomial logistic regression model for assessing factors associated with junk food consumption of secondary level students. Nep. J. Stat, 5, 2I-38. 